\title{
Ovarian torsion: appearance on MRI
}

\author{
Kai-Lun Cheng • Teng-Fu Tsao
}

Received: 20 January 2010/Revised: 18 February 2010/Accepted: 15 March 2010/Published online: 30 April 2010

(C) Springer-Verlag 2010

An 8-year-old girl presented with acute intermittent pain in the left abdomen with associated vomiting. US of the abdomen showed a pelvic ovoid mass. The T2-W MRI revealed an enlarged left ovary with multiple peripheral follicles (Fig. 1, short arrows) adjacent to a normal right ovary (Fig. 1, long arrow) consistent with left ovarian torsion. A necrotic ovary with peripheral follicles (Fig. 2, arrows) was removed at surgery.

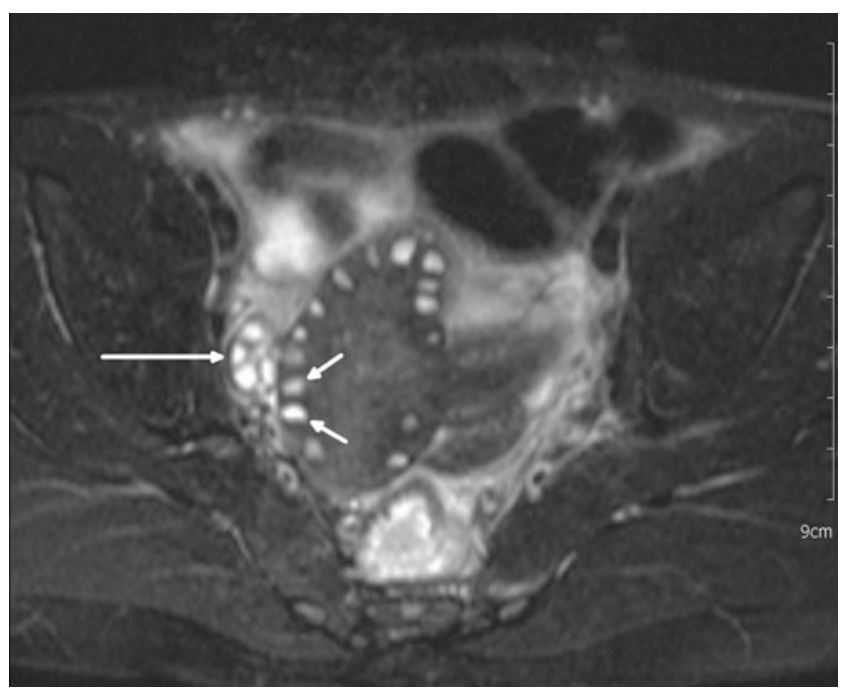

Fig. 1 Axial T2-W MRI

K.-L. Cheng · T.-F. Tsao $(\bowtie)$

Department of Medical Imaging, Chung Shan Medical University Hospital, School of Medical Imaging and Radiological Sciences,

Chung Shan Medical University,

Number 110, Section 1, Chien-Kuo N Road,

Taichung, Taiwan

e-mail: cshy1069@csh.org.tw

\section{T.-F. Tsao}

Department of Veterinary Medicine,

National Chung Hsing University,

Taichung, Taiwan

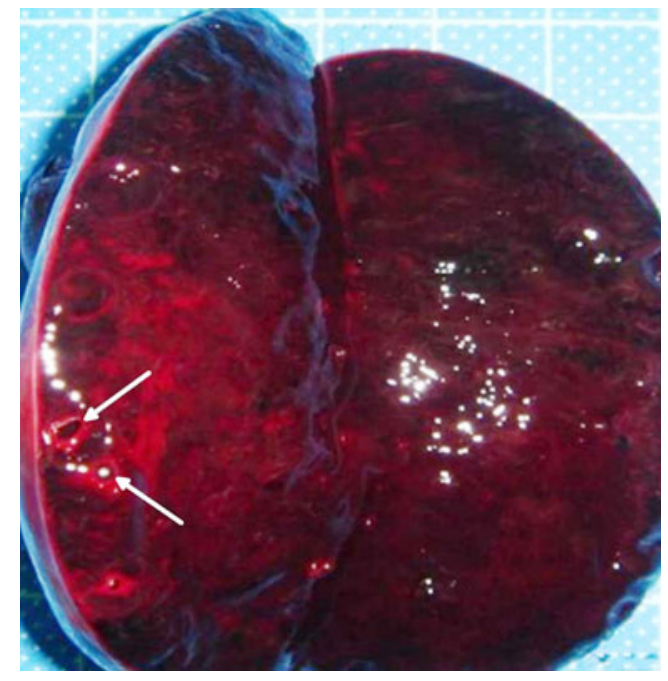

Fig. 2 Photograph of resected ovary

MR imaging findings in ovarian torsion vary depending on the stage of the disease. MR can be used in patients for whom US findings are inconclusive and can avoid exposing young patients to CT radiation. Typical early findings after torsion of the ovary are edematous enlargement of the ovary and the presence of multiple peripheral follicles caused by congestion. Later findings suggestive of torsion are smooth wall thickening of the twisted ovarian mass and uterine deviation to the twisted side [1].

\section{Reference}

1. Van Kerkhove F, Cannie M, Op de beeck K et al (2007) Ovarian torsion in a premenarcheal girl: MRI findings. Abdom Imaging $32: 424-427$ 